\title{
PEPTIDE MAPPING OF THE RIBULOSE BISPHOSPHATE CARBOXYLASE SMALL SUBUNIT FROM THE SOMATIC HYBRID OF TOMATO AND POTATO
}

by

\author{
CARSTEN POULSEN and DAN PORATH ${ }^{1}$ \\ Department of Physiology, Carisberg Laboratory \\ Gamle Carlsberg Vej 10, DK-2500 Copenhagen Valby
}

MARIA D. SACRISTÁN

Institut für Angewandte Genetik der Freien Universität Albrecht-Thaer-Weg 6. D-1000 Berlin 33

and

\section{GEORG MELCHERS}

Max-Planck-Institut für Biologie

Spemannstrasse $37 \mathrm{II}$, D-7400 Tübingen

1Present address: Department of Botany, The George S. Wise Faculty of Life Sciences, Tel Aviv University, Ramat-Aviv

Keywords: Fraction 1 protein, isoelectric focusing, chymotryptic peptides, tryptic peptides, protoplast fusion

Five somatic hybrids of potato and tomato obtained by protoplast fusion were identified using the isoelectric focusing patterns of ribulose bisphosphate carboxylase as phenotypic markers of the nuclear and chloroplast genomes. Together with the previously analyzed hybrids (14) this brings the number of verified somatic hybrids between the two species to nine. The products of both tomato and potato nuclear genomes are present in the ribulose bisphosphate carboxylase oligomer from all nine hybrids. Four of the hybrids contain the tomato large subunit and hence the tomato chloroplast DNA is functional, whereas in five hybrids the potato ribulose bisphosphate carboxylase large subunit and thereby the potato chloroplast DNA is present. The former are designated topatoes and the latter pomatoes (11).

Mapping of chymotryptic peptides of the small subunit of tomato and potato revealed a tyrosine containing peptide with species specific mobility. Peptide maps from an analyzed somatic hybrid contained both the tyrosine peptide specific for potato and that specific for tomato. Maps of tryptic peptides of the small subunit of tomato differed from those of the potato in 2 peptides. The tryptic peptide maps of one analyzed hybrid contained the two peptides unique to potato as well as the two peptides unique to tomato. The tomato-potato hybrids are aneuploid with chromosome numbers ranging from 48 to 74 , the expected allotetraploid number being 48 and the expected allohexaploid number 72 .

Abbreviations: RuBPCase $=$ ribulose-1,5-bisphosphate carboxylase; DTT $=$ dithiothreitol; SDS $=$ sodium dodecyl sulphate. 


\section{INTRODUCTION}

Four experimentally produced somatic hybrid plants of potato and tomato have been identified by using the enzyme ribulose-1,5-bisphosphate carboxylase as a marker for the nuclear and chloroplast genomes (14). Ribulose-bisphosphate carboxylase (RuBPCase) from higher plants is an oligomeric enzyme consisting of two polypeptides. The larger polypeptide with a molecular weight of 55,000 is coded for by a gene in chloroplast DNA and the smaller polypeptide with a molecular weight of 12,000 to 15,000 is encoded in a nuclear gene (see 23). If the parent plants differ in the structure of the small and large subunit of this enzyme, hybrids can be identified by analysis of this protein.

In the previous publication (14) it was shown that both the large and the small subunit of tomato and potato can be distinguished by the patterns obtained when the polypeptides are subjected to isoelectric focusing on gels. These differences were exploited to demonstrate the hybrid nature of four putative hybrid plants which had been regenerated from cells obtained after fusion of protoplasts from dihaploid potato $(2 n=24)$ and the yellow green tomato mutant yg6 $(2 n=24)$. Three of the plants with 50 to 57 chromosomes contained both the potato and the tomato small subunits of RuBCase but apparently only the large subunit of tomato. The nuclei of the fourth plant with 72 to 74 chromosomes also expressed the genes for the small subunits of both potato and tomato but the plant contained only or predominantly the large subunit of the potato. The prominence of the potato small subunit compared to that of the tomato in this plant suggested that it was a hybrid with 4 nuclear genomes of the potato and two of the tomato, the chloroplast genome being derived from the potato.

In the present paper we present the analysis of five additional putative somatic hybrids obtained as shoots differentiating on callus, which had been produced in the previously described fusion experiment (14) employing protoplasts from dihaploid potato and tomato. The potato protoplasts originated from white cells of a submersed callus culture and the tomato protoplasts from yellow-green mesophyll cells of leaves.

Chymotryptic and tryptic peptide maps of the RuBPCase small subunits from potato and tomato are compared in order to establish that their different isoelectric focusing patterns are due to different primary structures of this polypeptide chain. The potato and tomato small subunits are found to be distinguishable by the species specific mobility of one chymotryptic and two tryptic peptides. The somatic hybrids analyzed by peptide mapping of the small subunit contained the potato and tomato specific chymotryptic peptides as well as the species specific tryptic peptides.

\section{MATERIALS AND METHODS}

\subsection{Plant material}

The six somatic hybrids of tomato and potato used in this investigation have the designations: $2 a / 1 y / 7 c / S 14,2 a / 2 a / 36 d / S 3,6 a / 1 x / 5 d / S 6$, $6 \mathrm{~b} / 1 \mathrm{x} / 2 \mathrm{a}, 7 \mathrm{a} / 20 \mathrm{e} / \mathrm{S} 41,7 \mathrm{c} / 13 / \mathrm{S} 25$. They have been obtained by regeneration of protoplasts in the fusion experiment reported in Melchers, SACRISTÁn and Holder (14) employing mesophyll protoplasts from light green leaves of the mutant yellow green 6 (yg6) in Lycopersicon esculentum var. cerasiforme and protoplasts from a cell suspension culture of the dihaploid stock HH258 from Solanum tuberosum. Detailed protocols on the fusion, on the regeneration of protoplasts, the callus culture and the shoot regenerations of the plants obtained from the groups $7 \mathrm{a} / 20 \mathrm{e}, 6 \mathrm{a}, 6 \mathrm{~b}, 7 \mathrm{c}$ are given in the above mentioned publication (14). The plants from the group 2a were obtained in essentially the same way.

The plant $3 a / 2 b / S 1$ originated from a different fusion experiment employing protoplasts from a cell suspension culture of the dihaploid stock HH258 from Solanum tuberosum and mesophyll protoplasts from yellow green leaves of the mutant aurea (au) in Lycopersicon esculentum (3). No verified somatic hybrids have been obtained from the regeneration of protoplasts in this fusion experiment. For comparison plants of the dihaploid potato stock $\mathrm{HH} 258$ and the tomato mutant yg- 6 as well as tomato plants of the variety Supravite have been used.

\subsection{Isolation and purification of RuBPCase}

RuBPCase was isolated and purified from $5 \mathrm{~g}$ lots of fully expanded leaves according to the procedure described in Melchers, SACRISTÁN and Holder (14). 


\subsection{Sodium dodecyl sulphate polyacrylamide gel electrophoresis}

Homogeneity of RuBPCase preparations was tested by slab gel electrophoresis under denaturing conditions in $1 \mathrm{~mm}$ thick analytical $12.5 \%$ polyacrylamide gels, using the discontinuous alkaline buffer system of NevILLE (15). $100 \mu \mathrm{g}$ of enzyme was dissolved in $50 \mu \mathrm{l}$ of $0.1 \mathrm{M}-\mathrm{Na}_{2} \mathrm{CO}_{3}$, $0.1 \mathrm{~m}$-DTT and $50 \mu \mathrm{l}$ of $4 \% \mathrm{SDS}, 24 \%$ sucrose and $0.08 \%$ bromphenolblue. Full reduction and dissociation of the subunits was obtained by submersing the samples in a boiling waterbath for one minute immediately before application of $25 \mu \mathrm{l} \mathrm{samples} \mathrm{to} \mathrm{individual} \mathrm{slots.} \mathrm{Electrophoresis}$ was carried out for 18 hours at $17.5 \mathrm{~mA}$ and ambient temperature. The gels were stained with Coomassie blue.

\subsection{Modification of RuBPCase}

After dialysis against deionized water and freeze drying 10-20 mg purified enzyme was reduced and S-carboxymethylated as described by Hirs (6) assuming the presence of 96 moles of cysteines per mole of enzyme (mol. wt. $550,000)$. $25 \mu \mathrm{g}$ samples of the modified enzymes were also analyzed by SDS polyacrylamide gel electrophoresis as described above, except that DTT was omitted from the sample buffer.

\subsection{Isoelectric focusing of RuBPCase}

Isoelectric focusing of 25-50 $\mu \mathrm{g}$ of S-carboxymethylated enzyme from the above mentioned (2.1.) plants was carried out in two sets of experiments. In one set the isoelectric focusing and the following fixation, staining and destaining was carried out as described by Melchers et al. (14) employing $2 \%$ ampholine pH 5-7 (LKB, Sweden) as the ampholyte. In the second set this ampholyte of the gel was replaced by $2 \%$ pharmalyte $\mathrm{pH}$ 4.0-6.5 from Pharmacia, Uppsala, Sweden.

\subsection{Separation of the RuBPCase subunits}

Separation of the subunits of $10 \mathrm{mg}$ of freeze dried, S-carboxymethylated enzyme from potato, tomato mutant yg6 and the hybrids $7 \mathrm{c} / 13 / \mathrm{S} 25$ and $2 a / 2 a / 36 d / S 3$ as well as separation of the subunits of $10 \mathrm{mg}$ freeze dried unmodified enzyme from potato, tomato mutant yg6 and from the hybrid $6 \mathrm{~b} / 1 \mathrm{x} / 2 \mathrm{a}$ was undertaken on a $2.6 \times 30 \mathrm{~cm}$ column of Sephadex G-100 Fine, equilibrated in $50 \mathrm{~mm}$-ammonium bicarbonate pH 8.5 containing $0.5 \%$ SDS and $0.1 \% \mathrm{NaN}_{3}$. The S-carboxymethylated RuBPCases were dissolved in $2.5 \mathrm{ml}$ of this buffer before separation. The unmodified enzymes were dissolved in the buffer including $0.1 \mathrm{M}$-2-mercaptoethanol and reduced in a nitrogen atmosphere at $40^{\circ} \mathrm{C}$ for one hour prior to separation. After separation. the subunits were freeze dried and the SDS was removed thereafter by dissolving the subunit in 1 volume $10 \mathrm{~mm}-\mathrm{HCl}$ and thereafter precipitating the protein with 4 volumes of acetone. The precipitate was collected by centrifugation, resuspended in $0.1 \mathrm{M}-\mathrm{NaOH}$, dialyzed against 50 mu-ammonium bicarbonate for 24 hours and freeze dried (18).

\subsection{Performic acid oxidation}

Performic acid oxidation of $250 \mu \mathrm{g}$ of small subunit from potato, tomato mutant yg 6 and the hybrid $6 \mathrm{~b} / \mathrm{lx} / 2 \mathrm{a}$ was carried out as described by HiRS (5).

\subsection{Amino acid analysis}

Hydrolysis and amino acid analysis of small subunit samples was carried out as previously described for the large subunit of RuBPCase from barley (16). In all cases about $25 \mu \mathrm{g}$ of small subunit was hydrolyzed. The small subunit samples were obtained from the S-carboxymethylated enzymes of potato, tomato mutant yg6 and hybrid $2 \mathrm{a} / 2 \mathrm{a} / 36 \mathrm{~d} / \mathrm{S} 3$. Triplicate $25 \mu \mathrm{g}$ samples were hydrolyzed for 24,48 and 72 hours. The values for threonine, serine and tyrosine were obtained after extrapolation to zero time, whereas values for valine and isoleucine were those obtained after 72 hours of hydrolysis. For the analysis of cysteine and methionine, duplicate samples containing $25 \mu \mathrm{g}$ of performic acid oxidized small subunits from potato, tomato mutant yg6 and hybrid $6 \mathrm{~b} / 1 \mathrm{x} / 2 \mathrm{a}$ was hydrolyzed for 24 hours. Amino acid compositions were normalised to a common content of 9.0 moles of leucine. 


\subsection{Proteolytic degradation of small subunits}

The remaining $200 \mu \mathrm{g}$ (15 nmoles) of performic acid oxidized small subunits from potato, tomato mutant yg and hybrid $6 b / 1 x / 2 a$ were proteolytically degraded in $150 \mu \mathrm{l}$ of $0.1 \mathrm{M}$ ammonium bicarbonate for three hours at $32^{\circ} \mathrm{C}$ after the addition of $10 \mu \mathrm{l}$ from a $0.5 \mathrm{mg} \cdot \mathrm{ml}^{-1}$ of $\alpha$-chymotrypsin $(0.2$ nmoles).

50-70 nmoles of S-carboxymethylated small subunit from potato, tomato mutant yg and hybrid $2 \mathrm{a} / 2 \mathrm{a} / 36 \mathrm{~d}$ were digested in a similar way with the appropriate increases in volumes (500-700 $\mu$ l of buffer and adding 25-35 $\mu 1$ of $\alpha$ chymotrypsin solution). 30 nmole samples of $S$ carboxymethylated small subunit of RuBPCases from the same three plants were digested in 300 $\mu l$ of $0.1 \mathrm{M}$-ammonium bicarbonate for three hours at $32{ }^{\circ} \mathrm{C}$ after the addition of $15 \mu$ from a solution of $0.5 \mathrm{mg}$ of trypsin per $\mathrm{ml}$ of $10 \mathrm{~mm}$ $\mathrm{HCl}$. All digestions were terminated after the addition of glacial acetic acid until all bicarbonate had been removed as $\mathrm{CO}_{2}$. Subsequently, digests were separated in an appropriate number of tubes for peptide mapping.

\subsection{Peptide mapping procedures}

The chymotryptic digests of the performic acid oxidized small subunits (potato, tomato mutant yg6, 6b/1x/2a) were subjected to two dimensional thin layer chromatography on silica gel as described by Poulsen (16). Three 5 nmole samples from each of the three digests were chromatographed. Subsequently, the three sets of chromatograms were stained with cadmium ninhydrin, fluorescamine and with the amino

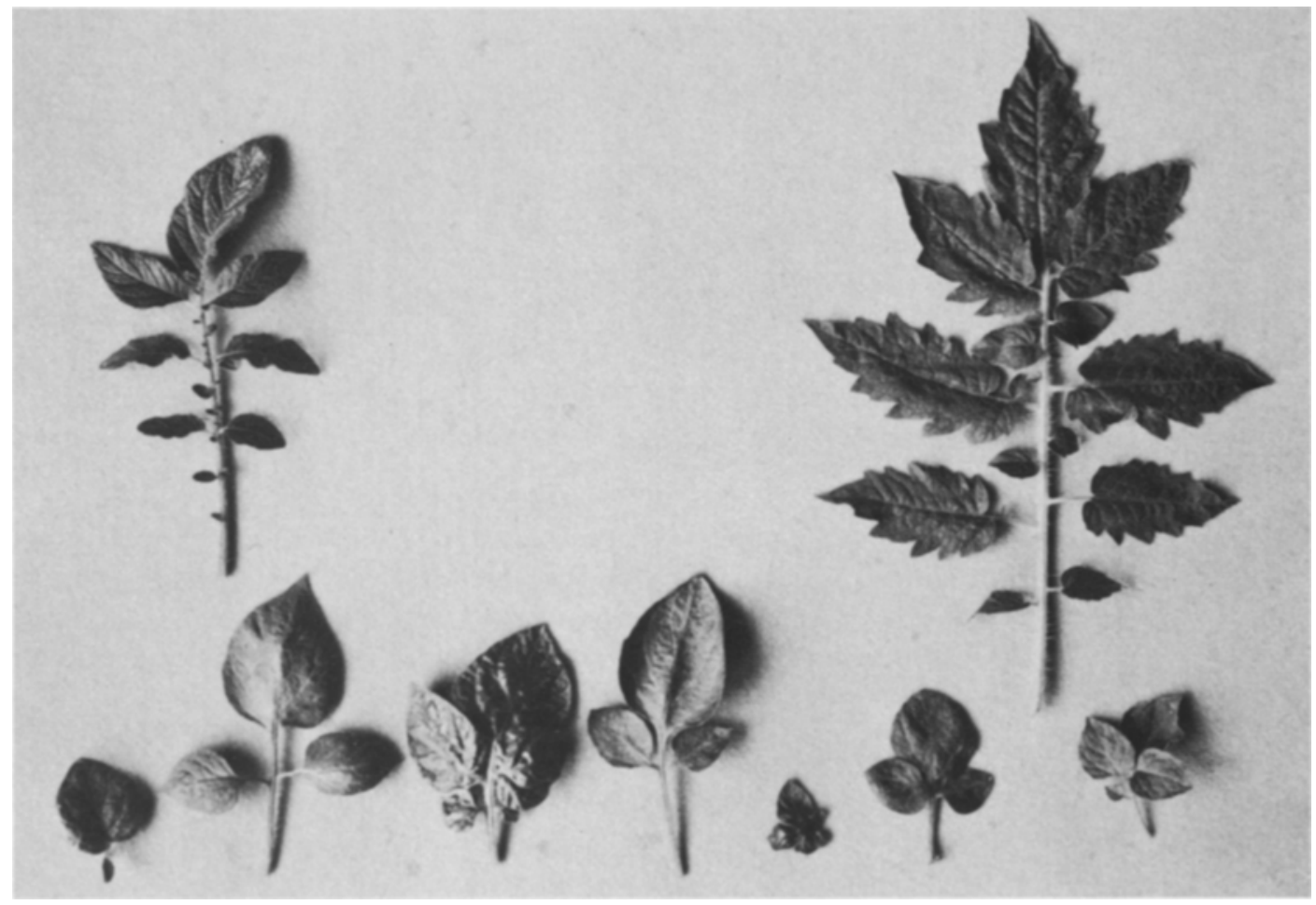

Figure 1. Leaves from somatic hybrids of potato and tomato regenerated from fused protoplasts.

Leaf of dihaploid potato $(\mathrm{HH} 258,2 \mathrm{n}=24)$ at upper left, leaf of tomato mutant yg6 $(2 \mathrm{n}=24)$ at upper right and leaves of their somatic hybrids below. The latter are from right to left: $6 \mathrm{~b} / 1 \mathrm{x} / 2 \mathrm{a}(50-52$ chromosomes), 7c/13/S25 (58 chromosomes), 7a/20e/S41 ( $~ 72$ chromosomes), 6a/1x/S6 (57 chromosomes), 2a/1y/7c/ $\mathrm{S} 14$ (60 chromosomes), $2 \mathrm{a} / 2 \mathrm{a} / 36 \mathrm{~d} / \mathrm{S} 3(\sim 48$ chromosomes). The leaf at far left is from plant $3 a / 2 b / \mathrm{S} 1$ regenerated from protoplasts of an unsuccessful experiment involving tomato mutant au. It contains only the small subunit of potato. 


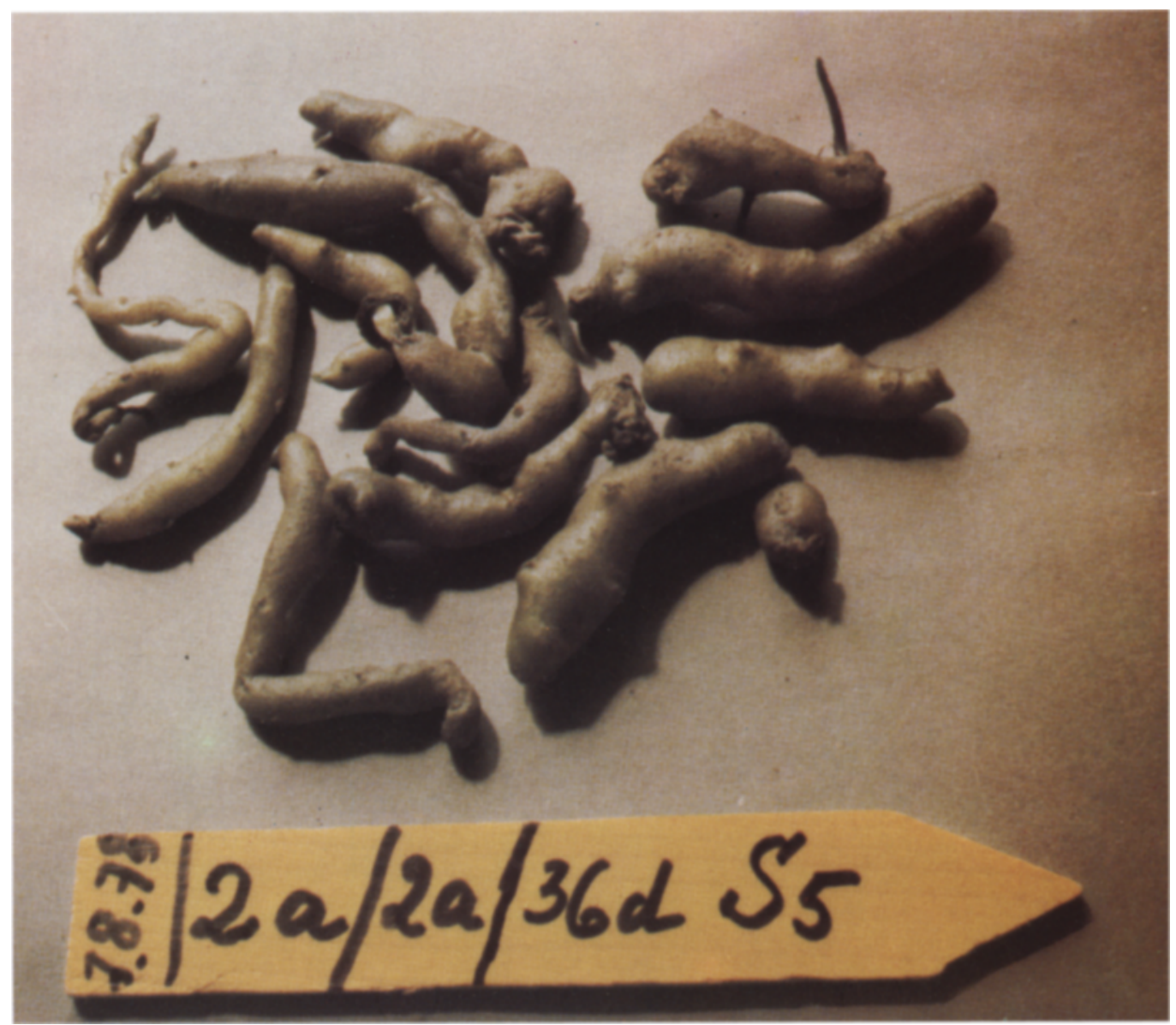

Figure 2. The somatic hybrid $2 \mathrm{a} / 2 \mathrm{a} / 36 \mathrm{~d} / \mathrm{S} 5$ forms small potato-like tubers. The tubers will sprout into new plants. The wooden label measures $11 \mathrm{~cm}$.

acid specific stains as described by HOLDER $(7,8)$ and by Poulsen (16). Thus, two plates from each set were stained with Cd-ninhydrin and with the tyrosine stain. The third plate was stained with fluorescamine followed by the arginine stain and Paulys reagent staining for tyrosine and histidine.

The chymotryptic digests of the S-carboxymethylated small subunits (potato, tomato mutant yg6 and $2 \mathrm{a} / 2 \mathrm{a} / 36 \mathrm{~d} / \mathrm{S} 3$ ) were subjected to thin layer electrophoresis and thin layer chromatography on cellulose thin layers as described by Poulsen (16). Five 10-15 nmole samples from each digest were used. Three plates from each set of digests were used for staining in the following combinations: Cadmium ninhydrin plus tyrosine-stain, cadmium ninhydrin plus Ehrlichs reagent for tryptophan and fluorescamine plus Paulys reagent.

Three 10 nmole samples from the tryptic digests of the S-carboxymethylated small subunits (potato, tomato, $2 \mathrm{a} / 2 \mathrm{a} / 36 \mathrm{~d} / \mathrm{S} 3$ ) were mapped for peptides in the same way as the corresponding chymotryptic digests, except that staining for arginine was included between staining with the fluorescamine and Paulys reagent.

\section{RESULTS}

\subsection{Morphological and cytological observations}

Leaves of the plants reported on in this paper are depicted in Figure 1. Generally the plants 
Table I

Verified somatic hybrids of tomato and potato. Plants $1 b / 2 h / 3 ; 6 a / 4 z / 6 g / S 2 ; 6 b / 1 x / 2 a$ and $7 a / 20 e / S 7$ were investigated previously (14), the others in the present paper.

\begin{tabular}{|c|c|c|c|c|c|c|}
\hline \multirow[b]{2}{*}{$\begin{array}{l}\text { Identifi- } \\
\text { cation }\end{array}$} & \multirow[b]{2}{*}{$\begin{array}{l}\text { Chromo- } \\
\text { somes }\end{array}$} & \multirow[b]{2}{*}{$\begin{array}{l}\text { Small subunit } \\
\text { Isoelectric } \\
\text { focusing }\end{array}$} & \multicolumn{4}{|c|}{ Ribulose bisphosphate carboxylase structure } \\
\hline & & & $\begin{array}{l}\text { SDS electro- } \\
\text { phoresis }\end{array}$ & $\begin{array}{c}\text { Peptide } \\
\text { maps }\end{array}$ & $\begin{array}{l}\text { Large subunit } \\
\text { Isoelectric } \\
\text { focusing }\end{array}$ & $\begin{array}{l}\text { SDS electro- } \\
\text { phoresis }\end{array}$ \\
\hline $1 \mathrm{~b} / 2 \mathrm{~h} / 3$ & 56 & potato + tomato & & & tomato & \\
\hline $2 \mathrm{a} / 1 \mathrm{y} / 7 \mathrm{c} / \mathrm{S} 14$ & 60 & potato + tomato & 1 band & & potato & 1 band \\
\hline $2 \mathrm{a} / 2 \mathrm{a} / 36 \mathrm{~d} / \mathrm{S} 3$ & $49(48)$ & potato + tomato & 1 band & potato + tomato & tomato & I band \\
\hline $6 \mathrm{a} / 1 \mathrm{x} / 5 \mathrm{~d} / \mathrm{S} 6$ & $57(56)$ & potato + tomato & 1 band & & potato & 1 band \\
\hline $6 \mathrm{a} / 4 \mathrm{z} / 6 \mathrm{~g} / \mathrm{S2}$ & 57 & potato + tomato & & & tomato & \\
\hline $6 b / 1 x / 2 a$ & $50-52$ & potato + tomato & 1 band & potato + tomato & tomato & 1 band \\
\hline $7 \mathrm{a} / 20 \mathrm{e} / \mathrm{S} 41$ & 72 & potato + tomato & 1 band & & potato & 1 band \\
\hline $7 \mathrm{a} / 20 \mathrm{e} / \mathrm{S} 7$ & $72-74$ & potato + tomato & & & potato & \\
\hline $7 \mathrm{c} / 13 / \mathrm{S} 25$ & 58 & potato + tomato & 1 band & & potato & I band \\
\hline
\end{tabular}

grow slowly and the number of leaves produced is limited. Propagation by cuttings and from small tubers (Figure 2) was however successful for the plant $2 a / 2 a / 36 d / S 3$. In this plant 49 , occasionally 48 chromosomes have been counted (Table I) which is in agreement with an expected amphidiploid number for a somatic hybrid of dihaploid potato $(2 \mathrm{n}=24)$ and tomato $(2 \mathrm{n}=$ 24) plus one extra chromosome. The latter is possibly derived from a trisomic cell of the submersed callus culture of the dihaploid potato used for protoplast formation in the fusion experiment. The cuttings of this plant gave enough leaf material usable for peptide mapping of the nuclear coded small subunit of ribulose bisphosphate carboxylase. The plants produce small flower buds but fruits or seeds are not obtained.

Also relatively vigorous are the scions from the regenerates $7 \mathrm{a} / 20 \mathrm{e}$ grafted on Supravite tomato stocks (Figure 8). They have chromosome numbers from 72 to 74 (Table I) and flower readily and form small aborting fruits. On their own roots these plants grow extremely slow. The excess of potato RuBCase small subunit over its tomato counterpart in this hybrid indicates that it contains 4 potato and 2 tomato genomes (14). A large number of cuttings with creaping growth was obtained from $2 \mathrm{a} / 1 \mathrm{y} / 7 \mathrm{c} / \mathrm{S} 14$ containing 60 chromosomes. The plants flower readily but no fruit set is obtained. The pollen grains of this hybrid vary widely in size and shape, most of them being dead. As expected from such an aneuploid, meiosis is irregular resulting in chromosomally unbalanced pollen mother cells.

The other plants studied gave chromosome counts between 50 and 60 (Table I) indicative of a high hyperploidy in the callus culture of the dihaploid potato $\mathrm{HH} 258$.

\subsection{Analysis of the RuBPCase preparations of the parents and hybrids}

As illustrated in Figure 3 all RuBPCase preparations analyzed were homogeneous by the criterion of sodium dodecyl sulphate polyacrylamide gel electrophoresis. Consistently only two bands were observed, one corresponding to the large subunit with an apparent molecular weight of 55,000 and the other corresponding to the small subunit with an apparent molecular weight of 12,000 . No differences in electrophoretic mobilities of the subunits are detectable, if reduced unmodified enzymes are compared with samples that have been modified by S-carboxymethylation prior to dissociation with SDS (Figure 3).

The large as well as the small RuBPCase subunits from potato and tomato can be distinguished by their species specific polypeptide patterns obtained by isoelectric focusing on gels (14). The S-carboxymethylated enzymes of the plants to be investigated were therefore subjected 


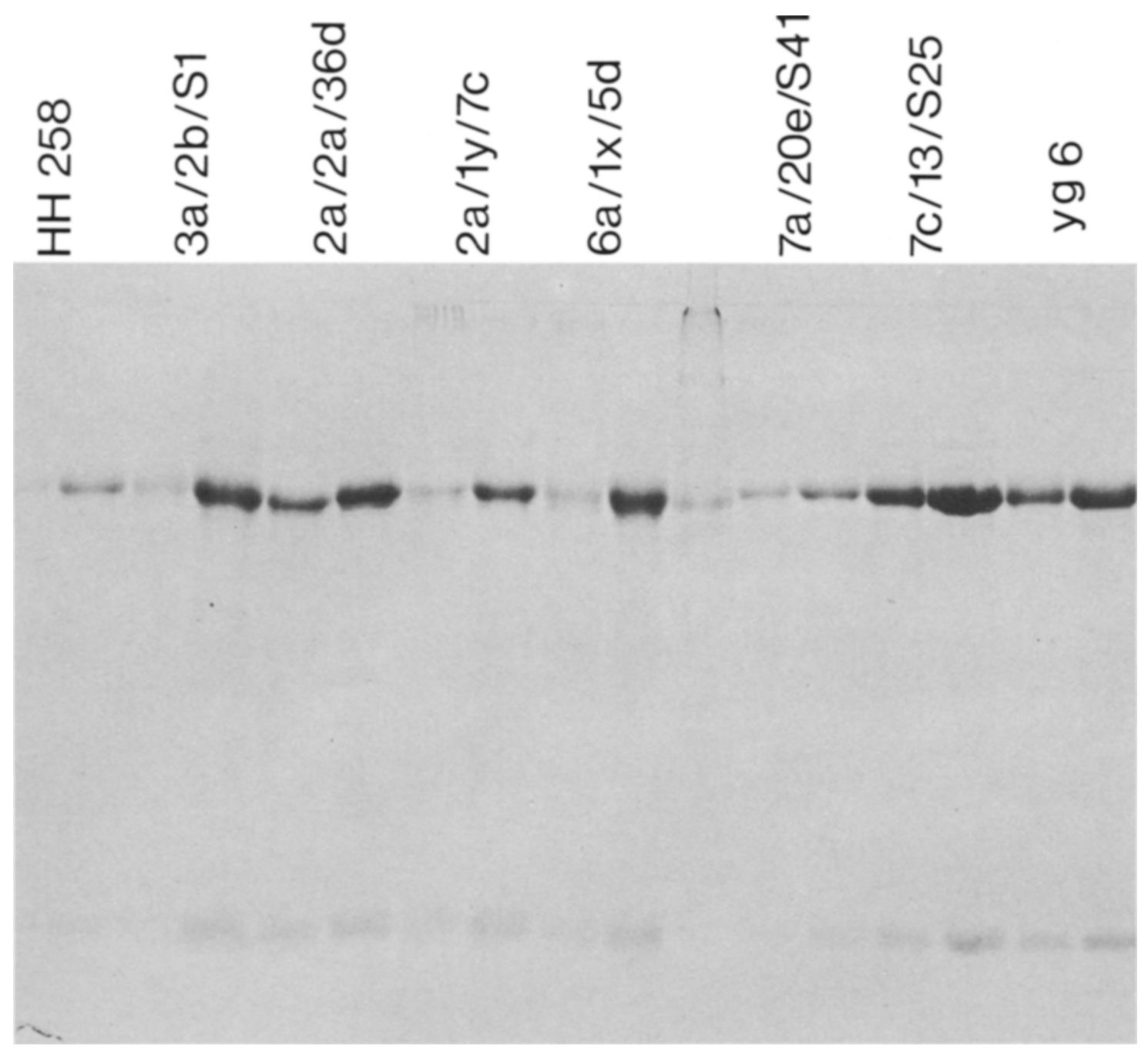

Figure 3. SDS polyacrylamide gel electrophoresis of ribulose bisphosphate carboxylase purified from dihaploid potato $(\mathrm{HH} 258)$, the tomato mutant yg6 and plants analyzed for their hybrid nature.

All enzyme preparations dissociated into 2 bands, the upper one with a mobility characteristic for the large subunit of the enzyme and the lower one typical for the small subunit of the enzyme. Track 11 from left contains purified large subunit of RuBCase from barley as a marker. For each enzyme preparation a reduced unmodified sample (right lane) and an S-carboxymethylated sample (left lane) was analyzed.

to isoelectric focusing under denaturing conditions using an LKB ampholine gradient $\mathrm{pH}$ 5-7 (Figure 4) and a Pharmacia pharmalyte gradient pH 4.0-6.5 (Figure 5). The large subunit as well as the small subunit revealed several variants with differing isoelectric points, those of the large subunit being positioned in the $\mathrm{pH}$-region between 5.8 and 6.5 and those of the small subunit in the pH-region between 5.2 and 5.6.
Although in the present experiment the large subunits separated into more variants with differing isoelectric points than in the previously reported studies (14) the major difference between tomato and potato large subunit is, as previously, the lower average isoelectric point of the variants from tomato than those from potato. This is apparent in a comparison of the lanes labelled HH258 (potato) with those labelled 
C. POULSEN et al: Somatic hybrid of tomato and potato

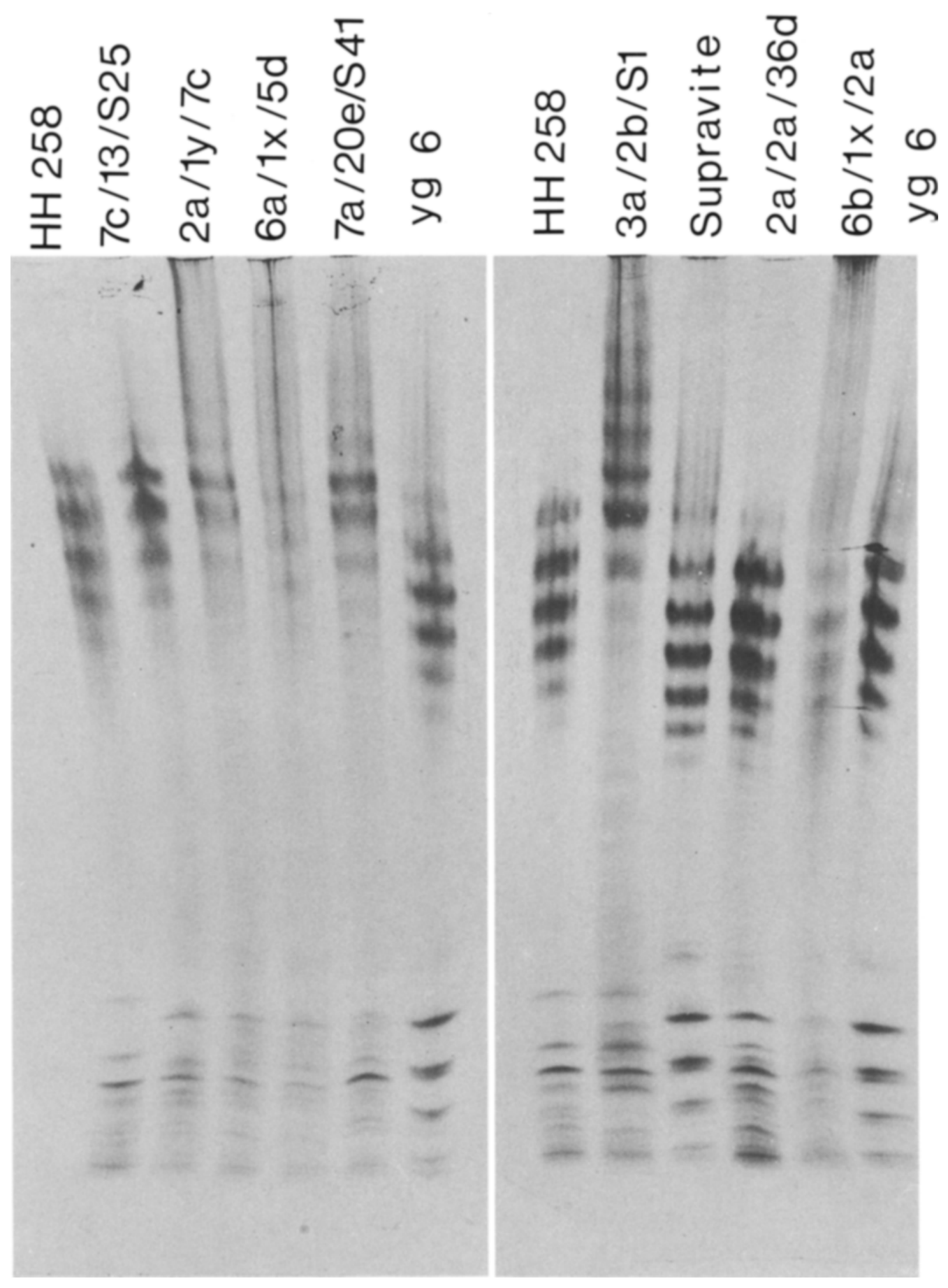

Figure 4. Isoelectric focusing of S-carboxymethylated RuBCase from potato (HH258), tomato mutant yg6 and plants analyzed for their hybrid nature.

Supravite is a disease resistant, well growing tomato hybrid variety. The experiment employed LKB amopholine $\mathrm{pH} 5$ (bottom) -7 (top). The upper group of bands belong to the large subunit and the lower group of bands to the small subunit. 

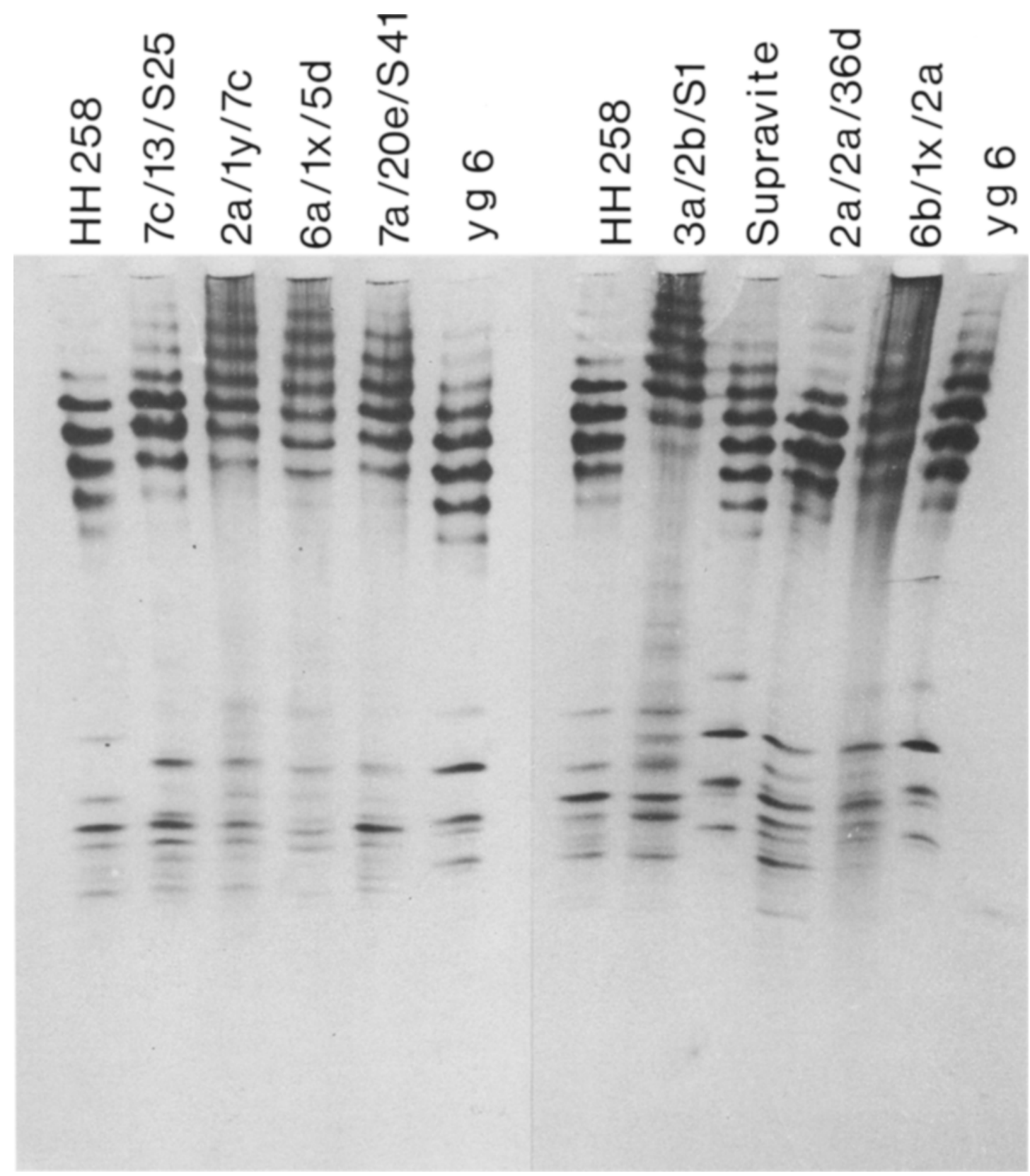

Figure 5. Isoelectric focusing of S-carboxymethylated RuBCase from potato (HH258), tomato mutant yg6 and plants analyzed for their hybrid nature.

Supravite is a standard tomato variety. The experiment employed Pharmacia pharmalyte $\mathrm{pH} 4.0$ (bottom)6.5 (top). The upper group of bands belong to the large subunit and the lower group of bands to the small subunit.

yg6 (tomato) and Supravite (tomato) in Figures 4 and 5 .

Of the five newly analyzed putative somatic hybrids four $(7 \mathrm{c} / 13 / \mathrm{S} 25,2 \mathrm{a} / \mathrm{ly} / 7 \mathrm{c}, 6 \mathrm{a} / 1 \mathrm{x} / 5 \mathrm{~d}$, $7 \mathrm{a} / 20 \mathrm{e} / \mathrm{S} 41)$ had a large subunit giving variants with a higher average isoelectric point than those 
of the tomato and thus resembling the large subunit of potato. It is concluded that these hybrids contain predominantly or exclusively RuBPCase with a large subunit coded for by the chloroplast DNA gene of potato.

The putative somatic hybrid $2 a / 2 a / 36 d / S 3$ contained a large subunit with an isoelectric focusing pattern indistinguishable from that of the tomato as was the case for the hybrid $6 \mathrm{~b} / 1 \mathrm{x} / 2 \mathrm{a}$ already analyzed in $1978(14)$. It is therefore concluded that these two hybrids contain predominantly or exclusively RuBPCase with large subunit coded for by the chloroplast DNA gene of tomato.

The isoelectric focusing patterns of the small subunit of RuBPCase from the tomato and potato were the same as reported previously (14) except that some additional bands can be observed in both patterns. The tomato small subunit pattern thus contained a weak band at the isoelectric point close to the most prominent potato band and a weak variant having a higher isoelectric point than any of the variants from the potato small subunit. The potato small subunit in turn gave rise to two very weak bands, which were electrofocusing just above the bottom band.

The small subunits of the putative somatic hybrids $(7 \mathrm{c} / 13 / \mathrm{S} 25,2 \mathrm{a} / 1 \mathrm{y} / 7 \mathrm{c}, 6 \mathrm{a} / 1 \mathrm{x} / 5 \mathrm{~d}$, $7 \mathrm{a} / 20 \mathrm{e} / \mathrm{S} 41,2 \mathrm{a} / 2 \mathrm{a} / 36 \mathrm{~d} / \mathrm{S} 3,6 \mathrm{~b} / 1 \mathrm{x} / 2 \mathrm{a})$ gave isoelectric focusing patterns which contained the three prominent tomato subunit bands (not found in the potato) as well as the prominent and three minor bands of the potato subunit without a counterpart in the tomato subunit pattern. These results reveal the five newly studied plants to form RuBPCase with potato and tomato small subunits. As the small subunit is coded for by a nuclear gene, tomato as well as potato genes for this polypeptide chain must be present in the nuclear genome of these plants, proving them to be somatic hybrids.

Plant $3 a / 2 b / S 1$ resulting from a fusion experiment between potato and the tomato mutant au contains a RuBPCase small subunit giving an isoelectric focusing pattern typical for the potato and lacking the variants diagnostic for the tomato small subunit. The large subunit has

\section{Table II}

Amino acid composition of small subunit of RuBPCase from potato, tomato and two somatic hybrids.

The amino acid values for tomato and potato are averaged values from analyses of S-carboxymethylated and performic acid oxidized samples of small subunits. The analyses are normalised to 9 moles of leucine.

\begin{tabular}{lcccc}
\hline & Potato HH258 & $2 \mathrm{a} / 2 \mathrm{a} / 36 \mathrm{~d}$ & $6 \mathrm{~b} / 1 \mathrm{x} / 2 \mathrm{a}$ & Tomato mutant yg6 \\
\hline Cya & 2.6 & - & 2.5 & 2.5 \\
CMCys & n.d. & 2.4 & - & 2.1 \\
& & & & \\
Asx & 9.1 & 9.2 & 8.5 & 8.8 \\
Thr & 5.0 & 4.8 & 4.5 & 4.7 \\
Ser & 4.5 & 4.1 & 2.9 & 5.2 \\
Glx & 15.8 & 16.1 & 15.2 & 16.5 \\
Pro & 6.6 & 6.5 & 6.6 & 6.5 \\
Gly & 7.0 & 7.0 & 6.3 & 7.0 \\
Ala & 5.8 & 5.5 & 5.1 & 5.7 \\
Val & 6.8 & 6.5 & 6.5 & 6.8 \\
Met & 2.2 & 2.3 & 2.1 & 2.3 \\
Ile & 4.9 & 4.8 & 4.8 & 4.8 \\
Leu & 9.0 & 9.0 & 9.0 & 9.0 \\
Tyr & 7.8 & 7.5 & 7.8 & 7.6 \\
Phe & 4.2 & 4.3 & 4.2 & 4.2 \\
His & 1.5 & 1.4 & 1.3 & 1.4 \\
Lys & 7.1 & 6.8 & 6.6 & 6.9 \\
Arg & 3.7 & 4.0 & 3.5 & 3.8 \\
Trp & n.d. & n.d. & n.d. & n.d. \\
\hline
\end{tabular}


a pattern of variants with abnormally high isoelectric points. The reason for this is unknown.

\subsection{Amino acid composition of the small subunit of RuBPCase from potato, tomato and their somatic hybrids}

Small subunits of RuBPCase from tomato, potato and the hybrids $2 \mathrm{a} / 2 \mathrm{a} / 36 \mathrm{~d} / \mathrm{S} 3$, $6 \mathrm{~b} / 1 \mathrm{x} / 2 \mathrm{a}$ and $7 \mathrm{c} / 13 / \mathrm{S} 25$ were isolated by gel filtration as described under 2.6 and analyzed for constituent amino acids. Table II lists the composition for potato, tomato and two of the hybrids. The differences between the four subunit preparations and that of the additional hybrid analyzed are small if at all significant. The overall amino acid composition of the small subunits gives no hint, how their primary structure differs between the tomato and potato as is expected from the analysis of the subunits by isoelectric focusing.

\subsection{Peptide mapping of the small subunit of RuBPCase from potato, tomato and a somatic hybrid}

The first attempts of peptide mapping were carried out with two dimensional thin layer chromatography on silica gels (16) after chymotryptic digestion of performic acid oxidized small subunits. The technique resolved fewer peptides than would be expected on the basis of the subunits' content of leucine, tyrosine and phenylalanine (tryptophan was destroyed by the oxidation). The maps of the subunit of tomato and potato were very similar but one peptide showed species specific mobility in both dimensions. The peptide from both species stained red with the cadmium ninhydrin reagent and with the tyrosine specific reaction employing 1nitroso-l-naphtol and nitric acid. The Pauly reagent also gave a positive purple reaction indicative of tyrosine, whereas the peptides did not stain for arginine. The high but species specific mobilities of the two peptides suggested them to be hydrophobic and of small size. In the analysis of the chymotrypsin digested small subunit from the hybrid $6 \mathrm{~b} / 1 \mathrm{x} / 2 \mathrm{a}$ both peptides were found to be present, supporting the evidence from isoelectric focusing that the hybrid contains both the potato and tomato small subunit.

More peptides could be resolved if thin layer electrophoresis in one direction was combined with thin layer chromatography in the second dimension using cellulose as support. The results of the separation of the chymotryptic peptides of the small subunit from tomato mutant yg6, potato line $\mathrm{HH} 258$ and the hybrid $2 \mathrm{a} / 2 \mathrm{a} / 36 \mathrm{~d} /$ $\mathrm{S} 3$ are presented in Figure 6 (left half). Using the amino acid specific stains 22 peptides could be identified in the map of the tomato as well as in the map of potato small subunit. A map prepared from the small subunit of the tomato variety Supravite was identical to that of the mutant line yg6.

Peptide number 18 of the tomato subunit had a different mobility than the corresponding peptide 18 of the potato when analyzed in relation to peptides $19,20,21$, and 22 . The peptide 18 stains specifically for tyrosine with both the 1-nitroso-2-naphtol and nitric acid reaction and with the Pauly reagent. In the chymotryptic peptide map of the hybrid $2 a / 2 a / 36 d / S 3$ both the peptide 18 from tomato (18T) and the peptide 18 from potato (18P) are present (cf. Figure 6 ). This provides evidence that the amino acid composition of peptide 18 in the tomato is different from peptide 18 in the potato and thus that the hybrid does express the nuclear genes coding for the small subunits of tomato as well as potato RuBPCase.

The tyrosine content of peptide 18 makes it likely that it is the same peptide showing species specific mobility in the peptide maps prepared by chromatography on silica gel as described above. It cannot be decided whether or not the chymotryptic peptide 18 contains histidine. The Pauly reagent stains for tyrosine and histidine, whereas the nitroso-naphtol procedure reacts only with tyrosine. There are probably only two histidine residues in the small subunit. As none of the 10 or 11 other chymotryptic peptides reacting with the Pauly reagent was negative for the nitroso-naphtol procedure, histidine cannot be assigned to a peptide. Peptides 18T and 18P are acidic when compared to the electrophoretic mobility of $\varepsilon$-DNP-lysine and their small size therefore makes it unlikely that they contain histidine.

In the chymotryptic peptide map of tomato a 


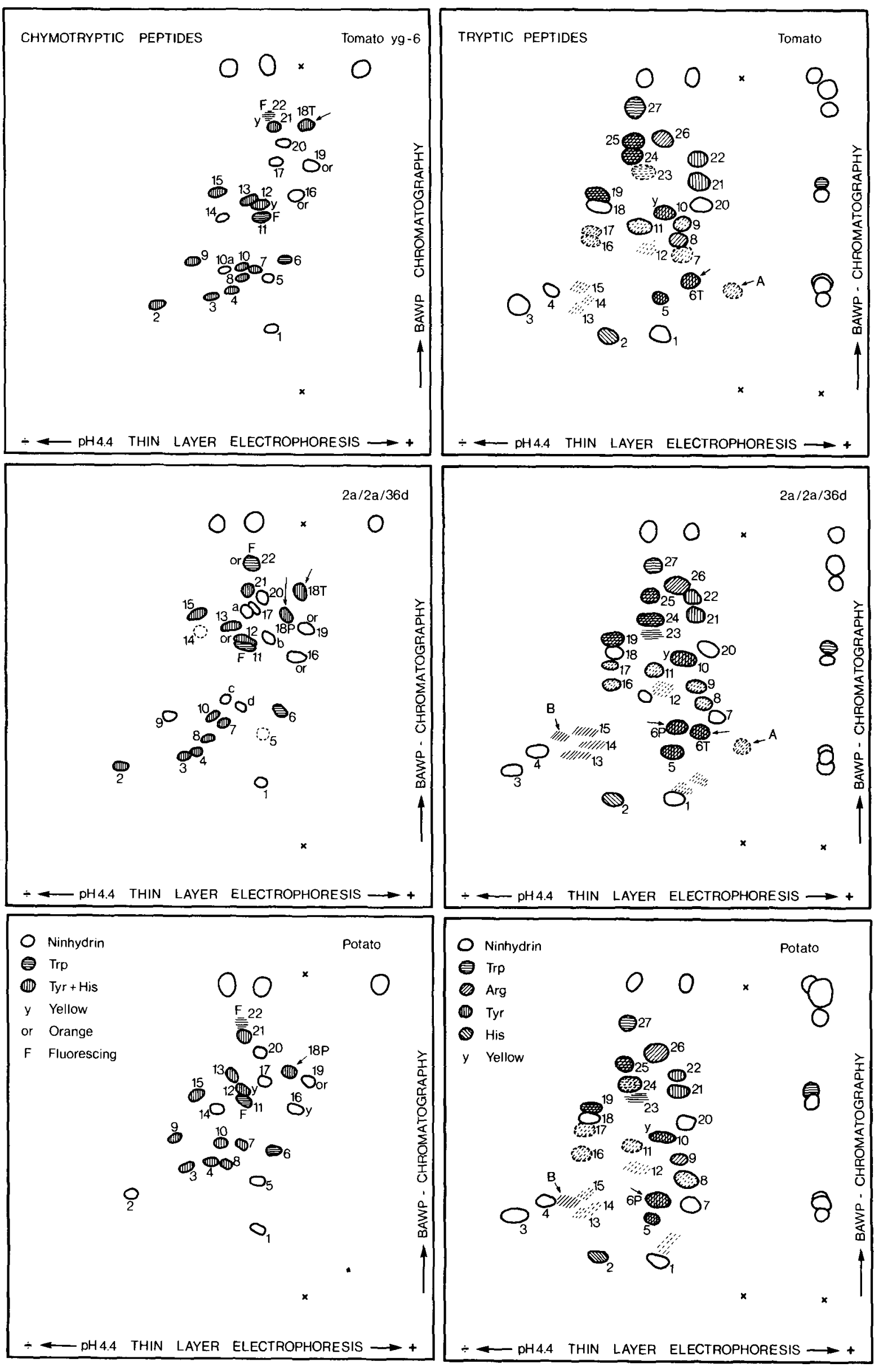


Figure 6. Peptide maps for the somatic hybrid $2 \mathrm{a} / 2 \mathrm{a} / 36 \mathrm{~d} / \mathrm{S} 3$ (middle) and its parents tomato mutant yg6 (top) and dihaploid potato (bottom).

Peptides diagnostic for potato and tomato are labelled with $\mathrm{P}$ and $\mathrm{T}$, respectively. BAWP $=$ butanol:acetic acid:water:pyridine. The reference amino acids at right are from bottom to top: Arg, Lys, Gly, His, Trp, DNP. Asp + Tyr, $\varepsilon$-DNP-Lys + Dansyl-Arg. The reference compounds at the top of the plate are from right to left: DNP-Asp, $\varepsilon$-DNP-Lys, Dansyl-Arg.

peptide labelled $10 \mathrm{a}$ was present which did not have a counterpart in the potato map or that of the hybrid. The map of the hybrid $2 \mathrm{a} / 2 \mathrm{a} / 36 \mathrm{~d} /$ $\mathrm{S} 3$ contained four additional peptides designated $a, b, c$, and $d$ not found in either parents. This was, however, accompanied by a drastic decrease in the intensity of cadmium ninhydrin staining of peptides 5 and 14 from the hybrid. These differences may find their explanation by additional proteolytic cleavage which has occurred during the digestion of the subunits of the hybrid, but not during digestion of the tomato and potato subunits.

A chymotryptic peptide map of the small subunit from the hybrid $7 \mathrm{c} / 13 / \mathrm{S} 25$ was very similar to that of the potato small subunit. Only one of the three thin layer plates revealed the presence of peptide 18 from tomato (18T). The peptide stained however very weakly, when compared to peptide 18 from potato (18P). The high aneuploid chromosome number of 58 in this hybrid suggests the presence of three or four potato chromosomes carrying the gene for the small subunit of RuBPCase in addition to the two tomato chromosomes. This can explain the preferential expression of the potato small subunit in the hybrid in question as a result of gene dosage.

The results of the separation of the tryptic peptides of the small subunits from tomato, potato and the hybrid $2 \mathrm{a} / 2 \mathrm{a} / 36 \mathrm{~d} / \mathrm{S} 3$ are presented in Figure 6 (right half). The three peptide maps are very similar and 27 peptides can be identified by their mobility and reaction with amino acid specific stains. The number of peptides produced by the tryptic digestion exceeds significantly the number expected from the 4 to 5 arginine and 7 to 8 lysine residues present in the small subunit. The trypsin treatment resulted in either incomplete digestion or cleavage of peptide bonds other than those formed by the carboxyl groups of lysine and arginine. As more than half of the tryptic peptides stain for arginine incomplete digestion is highly probable.

Species specific differences between tomato and potato comprise different mobility of tryptic peptide 6 (6T and 6P, respectively), the exclusive presence of peptide $A$ in the small subunit digest of tomato and the exclusive presence of peptide $\mathrm{B}$ in that of the potato. The hybrid $2 a / 2 a / 36 d / S 3$ contained among its tryptic peptides all four of these peptides. namely $6 \mathrm{~T}, 6 \mathrm{P}, \mathrm{A}$ and $\mathrm{B}$. The map also contained a peptide located between peptides 12 and 16 , not present in the tomato or potato maps.

The tryptic peptides 6T and 6P, characteristic for tomato and potato small subunit respectively, are tyrosine positive as were the species specific chymotryptic peptides $18 \mathrm{~T}$ and $18 \mathrm{P}$. It is therefore likely that the tryptic tomato peptide $6 \mathrm{~T}$ is distinguished from the tryptic potato peptide $6 \mathrm{P}$ by the same difference in amino acid sequence as the chymotryptic tomato peptide $18 \mathrm{~T}$ from the chymotryptic potato peptide $18 \mathrm{P}$. Conceivably the difference between the tomato tryptic peptide $\mathrm{A}$ and the potato peptide $\mathrm{B}$ involves the same species specific amino acid sequence, in which case only a limited sequence difference would distinguish the small subunits of RuBPCase from tomato and potato. It can be noticed that the tomato specific tryptic peptides $6 \mathrm{~T}$ and $\mathrm{A}$ are more acidic than the potato specific tryptic peptides $6 \mathrm{P}$ and $\mathrm{B}$. This corresponds to the tomato chymotryptic peptide $18 \mathrm{~T}$ being more acidic than the potato chymotryptic peptide $18 \mathrm{P}$.

\subsection{N-terminal amino acid sequence of the small subunit of RuBPCase from a somatic hybrid}

In an attempt to locate the species specific amino acid sequences from the potato and tomato small subunit A. A. Holder, B. MARTIN and I. SvEnDSEN determined the N-terminal 20 amino acid residues for the small subunit of 
RuBPCase from the somatic hybrid $6 \mathrm{~b} / 1 \mathrm{x} / 2 \mathrm{a}$ by automated Edman degradation.

The following sequence was obtained: MetGIn-Val-Trp-Pro-Pro-Ile-Asn-Val-Lys-Lys-TyrGlu-Thr-Leu-Ser-Tyr-Leu-Pro-Leu-.

This sequence is very similar to that determined for the small subunit of Nicotiana sylvestris (21). It is different by containing a valine instead of a lysine in position 9 and a leucine instead of an aspartic acid in position 20 . No polymorphism was encountered in this $\mathrm{N}$-terminal sequence comprising one fifth to one sixth of the total polypeptide of the small subunits of RuBPCase from the tomato-potato hybrid. The species specific difference must therefore be located in a different part of the polypeptide chain.

\section{DISCUSSION}

Table I summarizes the information now available on the verified somatic hybrids obtained by fusion of protoplasts from potato and tomato. Nine plants were shown to be hybrids by morphological characteristics and the isoelectric focusing pattern of the small subunit of RuBPCase. In two plants the presence of a tomato gene and a potato gene has been established at the level of the primary structure of the small subunit of RuBCase, as these hybrids contained the species specific chymotryptic and tryptic peptides of both potato and tomato. The isoelectric focusing patterns of the large subunit of RuBPCase revealed 4 hybrids to have the tomato subunit and 5 to contain the potato subunit. They may thus be called topatoes and pomatoes respectively (11). In contrast to the nuclear genomes of potato and tomato which are retained in the hybrid nucleus, the two chloroplast genomes of the fused cell seem to segregate somatically with the result that only one is eventually retained and expressed. In the verified hybrids approximately one half have retained the chloroplast genome of the tomato and one half that of the potato. The analysis does not exclude the possibility that the hybrids retain a small amount of unexpressed chloroplast DNA from the other species. The large variation in chromosome number makes it impossible to evaluate if the somatic segregation of the chloroplast genomes in the potato-tomato hybrid is influenced by interactions of the nuclear genomes with the chloroplast genomes or due to random sorting out.

For the somatic hybrid plants so far produced by protoplast fusion between species, which are probably impossible to hybridize sexually, it is characteristic that they are frequently aneuploid and that no fertile amphidiploids have been obtained: This applies to the hybrids of Datura innoxia and Atropa belladonna (9), to the hybrids of Arabidopsis thaliana and Brassica campestris (4) and to the hybrids of Petunia parodii and Petunia parviflora (20) as well as to the potato-tomato hybrids. However, some fertile amphidiploid somatic hybrids have been produced by protoplast fusion of lines and species, which can be hybridized sexually at least unilaterally e.g. in Nicotiana $(1,12)$ and Petunia (19). Aneuploids are also found in these cases $(10,13)$.

The aneuploidy of the somatic hybrids from species which cannot be hybridized sexually could be a result of genomic incompatibility leading to the elimination of certain chromosomes from the nucleus or the requirement for extra chromosomes of one species to balance deleterious effects of those from the other species. Chromosome elimination or the occurrence of other irregularities in connection with nuclear fusion and proliferation of the fused cells is indicated by the regeneration of shoots differing widely in morphology from the same hybrid callus. An example is given in Figure 7 showing a graft of shoot S26 from the callus $2 a / 1 y / 7 c$ to the left and to the right two grafts of shoot $S 18$ from the same callus. This shoot has strongly reduced leaf blades and is chlorophyll deficient, possibly signifying the loss of the potato chromosome with the wild type allele that covers the recessive yellow green allele of the tomato partner in the hybrid shoot $\mathbf{S 2 6}$. The latter is morphologically undistinguishable from shoot 14 of the callus $2 a / 1 y / 7 c$ shown to contain 60 chromosomes, the small RuBPCase subunits of potato and tomato and the large subunit of potato (Table I).

On the other hand it should be stressed that the regenerated plants and the 50 to 100 clonal individuals vegetatively propagated from some of them were stable and did not vary as to morphological or biochemical characteristics. This includes the green plants of $2 a / 1 y / 7 c / S 14$ with 60 chromosomes, the hexaploid or near hexa- 
ploid hybrid $7 \mathrm{a} / 20 \mathrm{e} / \mathrm{S} 7$ (Figure 8 ) as well as the near tetraploid hybrid $2 a / 2 a / 36 d / S 3$. The potato partners used to produce the potato-tomato hybrids were protoplasts obtained from a submersed callus suspension culture of a dihaploid potato stock. Regeneration of protoplasts from these potato callus yields up to $96 \%$ plants with a chromosome number at or close to the tetraploid level and $10 \%$ of the regenerated plants were aneuploids with chromosome number ranging from 37 to 50 chromosomes (22). Such a high number of aneuploids is not encountered when mesophyll protoplasts of the same dihaploid potato stock $(\mathrm{HH} 258)$ are regenerated but the regenerated plants are almost all tetraploid, whereas plants regenerated from microspores are diploid (dihaploid). Chromosome doubling is possibly caused by rotation of the submersed culture and by the auxins necessary during the in vitro culture for shoot regeneration and prolonged growth in the callus phase may increase the frequency of aneuploids (22). It is therefore considered likely that the aneuploidy and especially the hyperploidy of the potato genome in the potato-tomato hybrids is caused by the karyotype instability of the callus cultures used for potato protoplast production and of the callus cultures used for regenerating shoots in the fusion experiment. It is possible that the near hexaploid hybrids with 4 potato and 2 tomato genomes arise by fusion of a tetraploid potato protoplast with a diploid tomato protoplast rather than by triple fusion. It should be mentioned that the production of the aneuploid Datura innoxia-Atropa belladonna somatic hybrids (9), the aneuploid Arabidopsis thaliana-Brassica campestris hybrids (4) and the aneuploid Petunia parodii-Petunia parviflora hybrids (20) involved the use of colourless protoplasts from shoot and callus cultures in addition to callus culture of the fusion products.

Species specific allelic markers have previously been demonstrated at the level of the amino acid sequence and peptide maps for the small subunit of RuBPCase in Nicotiana sylvestris, tomentosiformis and tabacum, barley, pea, bean and Oenothera $(18,21,23)$. In the present paper peptide maps are presented which reveal differences in the primary structure of the small subunit of potato and tomato. The simultaneous presence in the hybrid of the potato and tomato specific tryptic as well as chymotryptic peptides authenticates the hybrid nature of the plants but also lend strong support to the inference that the differences in the isoelectric focusing patterns between the small subunit of tomato and potato are the results of differences in the primary structures of this polypeptide. In the present analysis surprisingly and fortunately the small differences in the peptide maps between potato and tomato causes such a large difference in the pattern of the isoelectric variants. The isoelectric variants are considered as different conformational states of the polypeptide chain and as such an expression of its primary structure. As discussed earlier (14) the number of variants of a given polypeptide chain can be influenced by posttranslational modification in the cell and by artefacts during enzyme isolation, purification, reduction or alkylation. From the successful application of isoelectric focusing patterns as phenotypic markers (e.g. 1, 20) it appears that such modification can serve to amplify the specific isoelectric focusing pattern inherent in the primary structure of the polypeptide. Present knowledge on the nature of isoelectric focusing patterns does unfortunately not permit deductions as to how many polypeptides with different primary structures are present in a protein preparation.

Species specific allelic markers at the level of the amino acid sequence and peptide maps for the large subunit of RuBPCase have been demonstrated for Nicotiana species, barley, spinach and Oenothera species $(2,8,16,17,23)$. The difference in the isoelectric focusing patterns between the potato and tomato large subunit of RuBPCase will have to be related to differences in their primary structure in future studies. It has been previously shown (14) that the number of isoelectric variants of the large subunit in potato is dependent on the isolation procedure. Especially, efficient removal of polyphenols during purification reduces the number of isoelectric variants and simplifies the patterns for the two species. In this respect the analyses in the present paper were less successful than in the previous study. However, the patterns obtained permitted to decide if a particular hybrid plant contained the large subunit of RuBPCase from potato or tomato. 


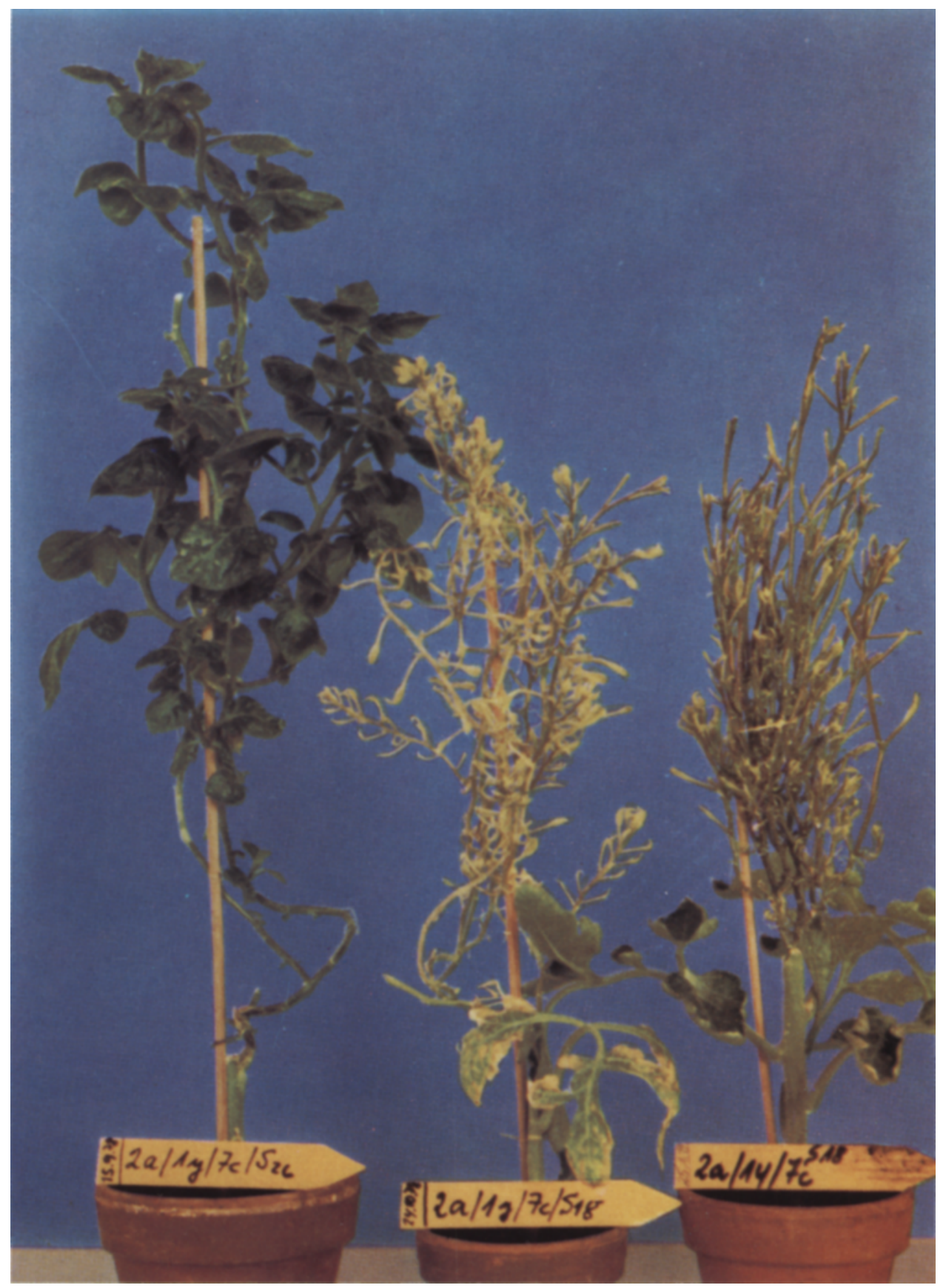

Figure 7. Comparison of different shoots obtained from the callus culture $2 \mathrm{a} / \mathrm{ly} / 7 \mathrm{c}$.

The callus could have arisen from a single fusion product or from several fusion products on the same dish. The shoots regenerated and grafted at left show strongly reduced leaf blades and are chlorophyll deficient. 


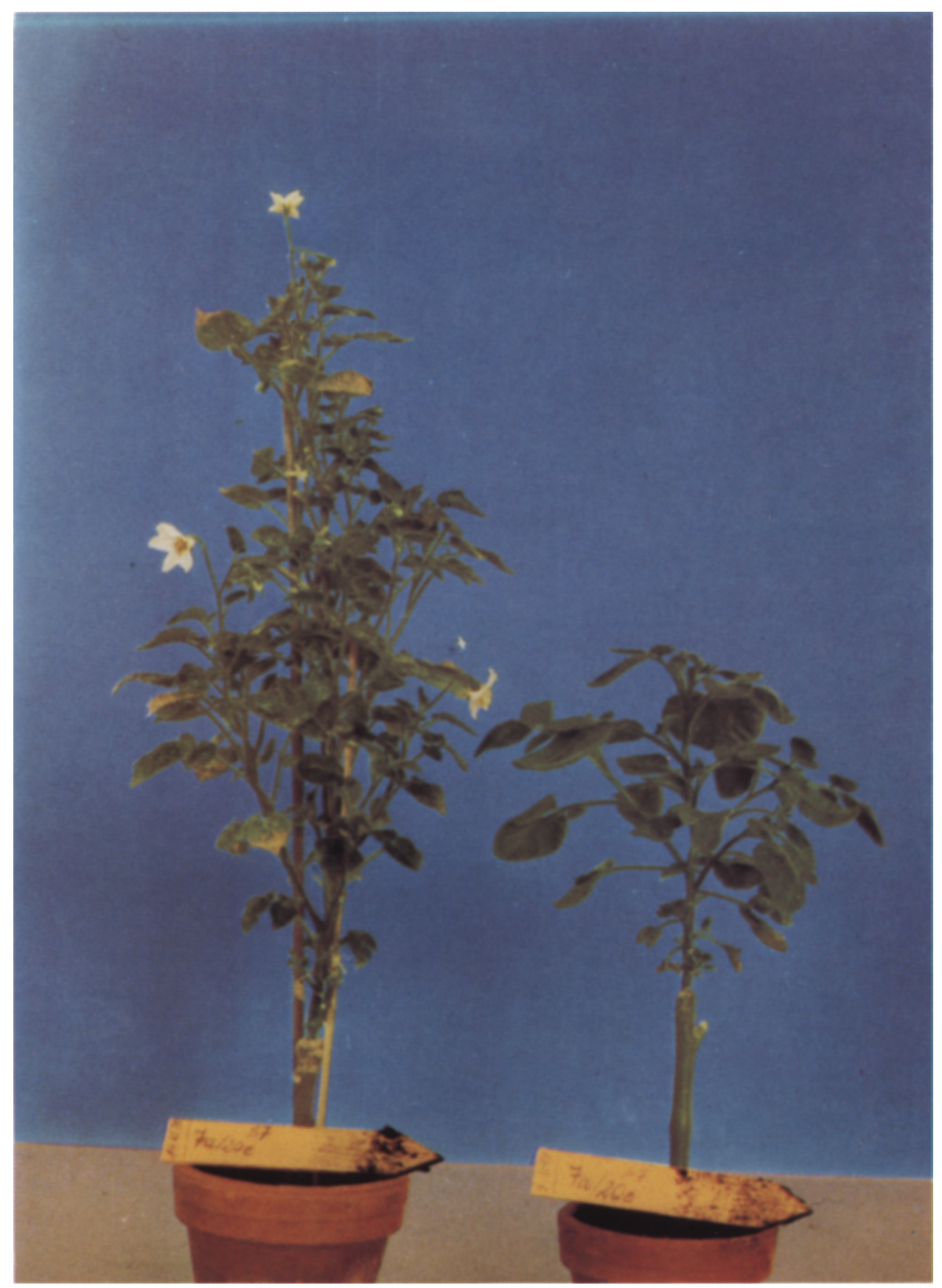

Figure 8. Hexaploid or near hexaploid potato-tomato hybrid ( $72-74$ chromosomes) which contains two tomato and four nuclear potato genomes.

The large subunit of RuBCase is of the potato type indicating that the plant has retained exclusively potato chloroplast DNA. 


\section{ACKNOWLEDGEMENTS}

We are grateful to Professor Diter voN WETTSTEIN for many helpful discussions and advices for preparation of the manuscript and to Drs. Anthony Holder, Brian Martin and Ib SVENDSEN for communicating to us the $\mathrm{N}$ terminal amino acid sequence of the small subunit of RuBPCase from the somatic potatotomato hybrid $6 \mathrm{~b} / 1 \mathrm{x} / 2 \mathrm{a}$. For outstanding technical assistance in Copenhagen we are indebted to Børge Petersen, Ann-Sofi Steinholtz and Bodil Corneliussen, for excellent assistance in Tübingen to Gudrun Labib, Inge DobrigkeIT and INGE RICKER.

\section{REFERENCES}

1. Aviv, D., R. Fluhr, M. Edelman \& E. Galun: Progeny analysis of interspecific somatic hybrids: Nicotiana tabacum (CMS) + Nicotiana sylvestris with respect to nuclear and chloroplast markers. Theor. Appl. Genet. 56, 145-150 (1980)

2. Chen, P.-M. \& S. G. Wildman: Chloroplast DNA codes for the primary structure of the large subunit of Fraction 1 protein. Biochim. Biophys. Acta 277, 677-680 (1972)

3. Clayberg, C. D., L. Butler, E. A. Kerr, C. M. Rick \& R. W. RoBinson: Condensed list of genes. Rep. Tomato Genet. Coop. 21, 2-9 (1971)

4. Gleba, J. J. \& F. Hoffmann: Plant-genome engineering by protoplast fusion. Naturwissenschaften 66, 547-554 (1979)

5. Hirs, C. H. W.: Performic acid oxidation. In: Methods in Enzymology, C. H. W. Hirs ed. Academic Press, New York and London, Vol. XI, pp. 197-199 (1967)

6. HiRs, C. H. W.: Reduction and S-carboxymethylation of protein. In: Methods in Enzymology; C. H. W. Hirs ed., Academic Press, New York and London, Vol. XI, pp. 199-203 (1967)

7. HOLDER, A. A.: Ribulose-1,5-diphosphate carboxylase from Oenothera. Purification and a peptide mapping procedure for the subunits. Carlsberg Res. Commun. 41, 321-334 (1976)

8. Holder, A. A.: Peptide mapping of the ribulose bisphosphate carboxylase large subunit from the genus Oenothera. Carlsberg Res. Commun. 43, 391-399 (1978)

9. Krumbiegl, G. \& O. Schieder: Selection of somatic hybrids after fusion of protoplasts from Datura innoxia and Atropa belladonna. Planta 145, 371-375 (1979)

10. Melchers, G.: Microbial techniques in somatic hybridization by fusion of protoplasts. In:
International Cell Biology 1976-1977. B. R. Brinkley and K. R. Porter eds. The Rockefeller University Press p. 207-213 (1977)

11. Melchers, G.: Protoplast fusion, mechanism and consequences for potato breeding and production of potato + tomatoes. In: Advances in Protoplast Research. Akadémiai Kiadó, Budapest, pp. 283-286 (1980)

12. Melchers, G. \& G. LabiB: Somatic hybridization of plants by fusion of protoplasts. I. Selection of light resistant hybrids from whaploid light sensitive varieties of tobacco. Molec. gen. Genet. 135, 277-294 (1974)

13. Melchers, G. \& M. D. Sacristán: Somatic hybridization of plants by fusion of protoplasts II. The chromosome numbers of somatic hybrid plants of 4 different fusion experiments. In: La Culture de tissus et des cellules des végétaux. Masson, Paris p. 169-177 (1977)

14. Melchers, G., M. D. Sacristán \& A. A. Holder: Somatic hybrid plants of potato and tomato regenerated from fused protoplasts. Carlsberg Res. Commun. 43, 203-218 (1978)

15. Neville Jr., D. M.: Molecular weight determination of protein-dodecyl sulfate complexes by gel electrophoresis in a discontinuous buffer system. J. Biol. Chem. 246, 6328-6334 (1971)

16. Poulsen, C.: The cyanogen bromide fragments of the large subunit of ribulose-bisphosphate carboxylase from barley. Carlsberg Res. Commun. 44, 163-189 (1979)

17. Poulsen, C., B. Martin \& I. Svendsen: Partial amino acid sequence of the large subunit of ribulose bisphosphate carboxylase from barley. Carlsberg Res. Commun. 44, 191-199 (1979)

18. Poulsen, C., S. Strgbek \& B. G. Haslett: Studies on the primary structure of the small subunit of ribulose-1,5-diphosphate carboxylase. In: Genetics and biogenesis of chloroplast and mitochondria. Th. Bücher et al., Elsevier/North Holland, Biomedical Press, Amsterdam, pp. 1724 (1976)

19. Power, J. B., S. F. Berry, J. V. Chapman, E. C. Cocking \& K. C. SinK: Somatic hybrids between unilateral cross-incompatible Petunia species. Theor. Appl. Genet. 55, 97-99 (1979)

20. Power, J. B., S. F. Berry, J. V. Chapman \& E. C. Cocking: Somatic hybridization of sexually incompatible Petunias: Petunia parodii, Petunia parviflora. Theor. Appl. Genet. 57, 1-4 (1980)

21. Strøbek, S., G. C. Gibbons, B. Haslett, D BOUL.TER \& S. G. WILDMAN: On the nature of the polymorphism of the small subunit of ribulose-1,5-diphosphate carboxylase in the amphidiploid Nicotiana tabacum. Carlsberg Res. Commun. 41. 335-343 (1976) 


\section{Poulsen et al.: Somatic hybrid of tomato and potato}

22. Wenzel, G., O. Schieder, T. Przewozny, S. K. Sopory \& G. Melchers: Comparison of single cell culture derived Solanum tuberosum L. plants and a model for the application in breeding programs. Theor. Appl. Genet. 55, 4955 (1979)
23. Wettstein, D. von, C. Poulsen \& A. A. HOLDER: Ribulose-1,5-bisphosphate carboxylase as a nuclear and chloroplast marker. Theor. Appl. Genet. 53, 193-197 (1978) 